\title{
Supports From Parents, Optimism, and Life Satisfaction in Early
} Adolescents

\author{
Shue Ling Chong, Rozumah Baharudin ${ }^{*}$
}

Department of Human Development and Family Studies, Faculty of Human Ecology, Universiti Putra Malaysia, Malaysia

*Corresponding author: rozumah@upm.edu.my

\begin{abstract}
This study examined influences of father and mother support, and optimism on life satisfaction in early adolescents $(\mathrm{n}=814$; mean age $=13.66$ years old) in Malaysia, as well as its variation across gender. Participants were recruited using Probability Proportional to Size (PPS) sampling method from secondary school of four educational zones in Kuala Lumpur. Questionnaires comprising demographic items and measures of the social support, optimism and life satisfaction were self-administered by the students at their respective schools. Data were analyzed using descriptive and inferential statistics including Structural Equation Modeling (SEM) via AMOS. Adolescents who received greater support from their parents reported better life satisfaction. Optimism has an indirect effect on relationship between support from mother and life satisfaction. The model was found as not stable across gender. Support from mother contributed to optimism, and optimism contributed to life satisfaction among adolescent boys, while effect was not found among adolescent girls. Findings imply the importance of considering these variables in prevention and intervention efforts involving early adolescents.
\end{abstract}

Keywords: Parental support, optimism, life satisfaction, gender, early adolescents

(C) 2017 Penerbit UTM Press. All rights reserved

\subsection{INTRODUCTION}

Life satisfaction is an overall judgment process of an individual towards their life as a whole (Diener, Emmons, Larsen, and Griffin, 1985). There is a growing body of research in life satisfaction and wide array of positive outcomes are associated with life satisfaction, such as better academic achievement and school engagement, higher self-esteem, more self-actualizing symptoms, and fewer externalizing behaviors (Suldo and Huebner, 2004a; Gracia, 2013; Moksness \& Espnes, 2013; Salmela-Aro \& Tuominen-Soini; 2010). Therefore, there is a need to identify factors which predicts life satisfaction to promote life satisfaction of adolescents.

Review of literature reveals the importance of parental factors on adolescents life satisfaction, including parental involvement, parent child relationships and parental support (Ash \& Huebner, 2001; Flouri \& Buchanan, 2002; Gilham \& Huebner, 2006, Suldo \& Huebner, 2004b; Zimmerman, Salem, \& Maton, 1995). Among all the parental factors, supports from parents emerged as a critical factor that contribute to adolescents' life satisfaction (Suldo \& Huebner, 2006). Supports from parents is a necessary factor for high level of life satisfaction in adolescents.

Apart from supports from parents, research shows that optimism contributes to well-being of adolescents, in which life satisfaction is a key indicators of well-being (e.g., Creed, Patton, and Bartum, 2002; Chong Huan, Yeo, and Ang, 2006). Optimism is the tendency to expect positive things to happen in future (Scheier, Carver, \& Bridges, 1994). Optimistic adolescents are expected to have higher life satisfaction given their positive expectancy towards future.

Given the importance of both supports from parents and optimism in adolescents' life satisfaction, this study aims to study the interplay among these there variables, namely supports from parents (father and mother), optimism, and life satisfaction in adolescents.

\subsection{THEORETICAL FOUNDATION OF THE STUDY}

Bandura's Social Cognitive Theory is the underpinning theory that guides this study. Bandura proposed triadic reciprocal determinism model whereby environmental factors, personal factors, and behavior/outcome, will influence each other in reciprocal directions (Bandura, 1978) as shown in Figure 1. Each factor will influence each other as respective strengths and magnitude increases. For example, in this study, as supports from parents become stronger, optimism level and life satisfactions level will increases too. 


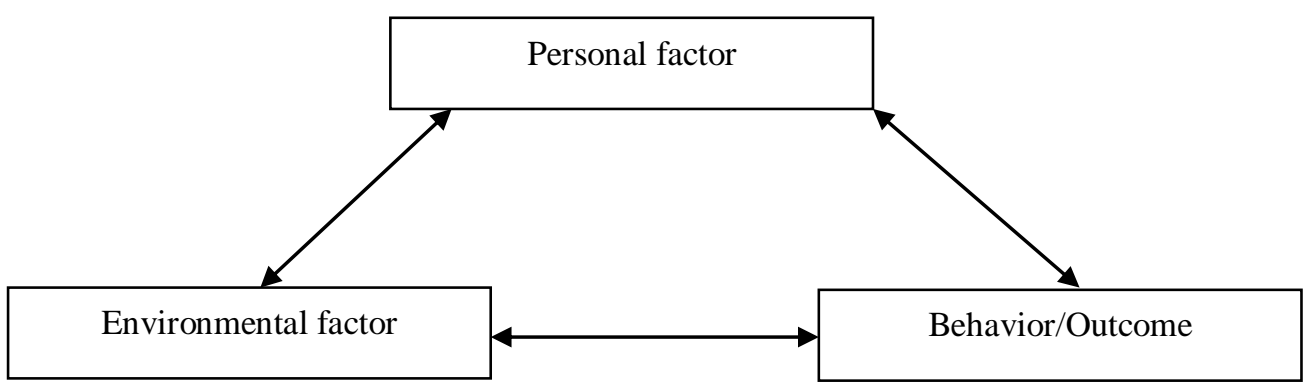

Figure 1 Bandura's social cognitive theory

\subsection{CONCEPTUAL FRAMEWORK}

Conceptual framework for this study is developed based on Bandura's Social Cognitive Theory (Figure 2). Supports from parents which serves as the environment factor is expected to predict life satisfaction in adolescents, which optimism and pessimism (personal factors) are expected to mediate the relationships between supports from parents and life satisfaction.

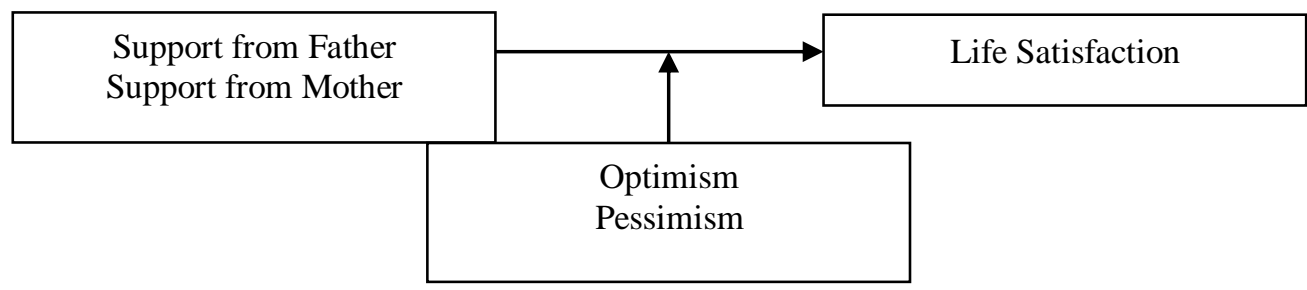

Figure 2 Conceptual framework

\subsection{RESEARCH OBJECTIVES}

This study aims to investigate relationships between supports from parents (father and mother) and life satisfaction in adolescents, as well as mediation role of optimism and pessimism, and moderation role of gender.

Specific objectives:

1. To examine the relationships between supports from parents (father and mother) and adolescents' life satisfaction.

2. To examine the extent to which optimism mediates the structural relationships between supports from parents (father and mother) and adolescents' life satisfaction.

3. To examine the extent to which pessimism mediates the structural relationships between supports from parents (father and mother) and adolescents' life satisfaction.

4. To examine the extent to which sex moderates the structural relationships between supports from parents (father and mother) and adolescents' life satisfaction.

\subsection{METHODOLOGY}

This is a quantitative study, which employs survey questionnaire to collect data from participants. Survey design has a good generalization of data with is capable of recruiting large sample size at low cost.

Location

This study was conducted in Kuala Lumpur, in all four educational zones, namely Bangsar/Pudu, Keramat, Sentul, and Wangsa Maju. Research was conducted in ten schools, randomly selected from the four educational zones.

\section{Participants}

Participants were recruited using Probability Proportional to Size (PPS) sampling method from secondary school of four educational zones in Kuala Lumpur. There are total of 814 participants involved in this study, range from 13 to 14 years old $($ mean age $=13.66)$. 


\section{Research Instrument}

As mentioned in research objectives, there are five major constructs in this study, namely: support from father, support from mother, optimism, pessimism, and life satisfaction. In order to measure the above mentioned construct, a set of questionnaire consisted the following instruments was used in data collection.

1. Student's Life Satisfaction Scale (SLSS)

SLSS measures adolescent's life satisfaction by requesting adolescents to rate their quality of life in general (Huebner, 1995). There are seven items in SLSS, in which students rated their responses on a 6-point Likert scale: strongly disagree (1), moderately disagree (2), mildly disagree (3), mildly agree (4), moderately agree (5), and strongly agree (6). Total score was obtained by summing up score for each item after reverse coding for item 3 and 4 . A higher score indicated higher satisfaction towards life. Cronbach alpha for SLSS in this study is 0.58 .

2. Child and Adolescent Social Support (CASSS)

CASSS measures adolescent's social supports from parents, teachers, class mates, and close friends (Malecki \& Demaray, 2002). However, this study only employed parents subscale. The subscale was further divided into supports from father and supports from mother to measures parental supports from both parents separately. There are 12 items in parents subscales, in which students rated their responses in a 6-point Likert scale, ranging from never (1) to always (6). Total scores was obtained by summing up scores for each item. A higher score indicated higher parental support. Cronbach alpha for Mother subscale is 0.92 , while cronback alpha for Father subscale is 0.95 in this study.

3. Life Orientation Test-Revised (LOT-R)

LOT-R measures positive expectancy of an individual towards future (Scheier, Carver, and Bridges, 1994). LOT-R consists of tem items with four filler items, which was excluded from total score. There are two subscales in LOT-R, namely optimism and pessimism, with three items respectively. Total score for each subscale was obtained by summing up score of each item. As for pessimism subscale, items were reverse coded before summing up the total score. Cronbach alpha for Optimism subscale is 0.56 and 0.60 for Pessimism subscale respectively.

Apart from that, demographic information including age and gender were collected for analysis purpose too.

\subsection{RESULTS AND DISCUSSION}

\section{Data Analysis}

This study employs structural equation modeling (SEM) to test the plausibility of the model specified in Figure 2 . The overall model fit was examined. Simultaneously, the significance and direction of the regression estimates were examined.

The following steps were taken for data analysis. First, a measurement model was established and its model fit was examined. Next, a structural model was built and its model fit was examined. After that, mediation analysis was carried out using bootstrapping method. Lastly, the fit model was tested for gender invariance to cross validate the structural model.

\section{Measurement Model}

The fit of measurement model was excellent, with Chi-square $\chi^{2}(137)=376.30, p=.00$, Root Mean Squared Error of Approximation $($ RMSEA $)=0.46$, Tucker-Lewis Index $(\mathrm{TLI})=.96$, and Comparative Fit Index $(\mathrm{CFI})=.97$. Parceling was used in each construct to further improve the model fit. The result of measurement model shows that each construct was sufficiently measured by the number of items in each construct.

\section{Structural Model}

The hypothesized model was tested using SEM. Figure 3 showed excellent fit of structural model with Chi-square $\chi^{2}(138)=387.06, p=$ .00 , Root Mean Squared Error of Approximation $($ RMSEA $)=0.47$, Tucker-Lewis Index $(\mathrm{TLI})=.96$, and Comparative Fit Index $(\mathrm{CFI})=$ .97.

Structural regression weights of structural model were further examined. Support from mother is significantly associated with life satisfaction $\left(\beta_{\text {standardized }}=0.26, p<0.00\right)$, and optimism $\left(\beta_{\text {standardized }}=0.25, p=0.002\right)$. Support from father is significantly associated with life satisfaction $\left(\beta_{\text {standardized }}=0.37, p=0.002\right)$. At the same time, optimism is significantly associated with life satisfaction $(\beta$ standardized $=$ $0.116, p=0.049)$, while pessimism is significantly associated with life satisfaction $(\beta$ standardized $=0.11, p=0.03)$. However, no significant association found between support from father, with optimism and pessimism; and also support from mother and pessimism. 


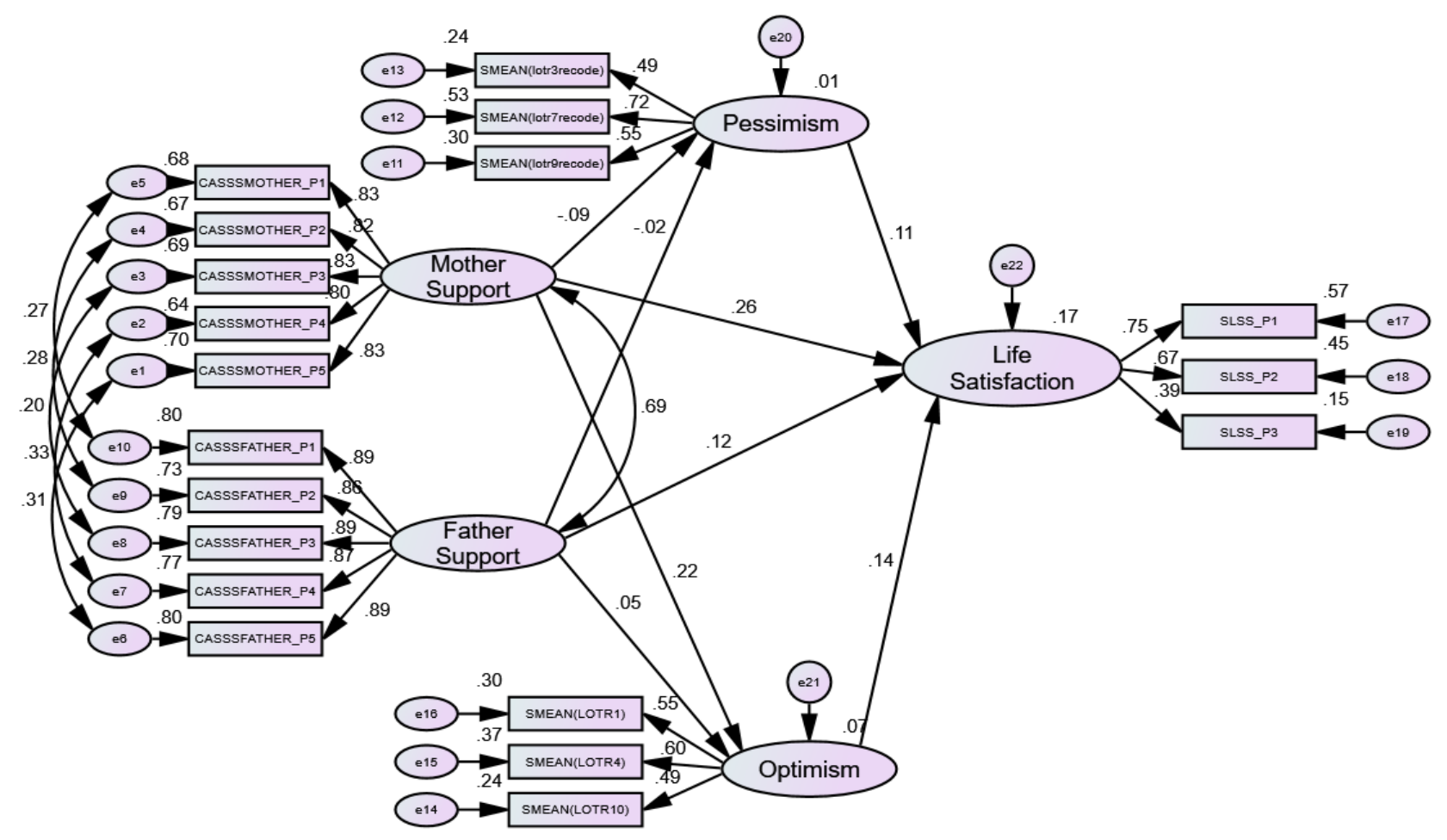

Figure 3 Structural model with standard estimates

\section{Testing Indirect Effect}

Bootstrap analysis was conducted in order to examine mediation effect of both optimism and pessimism on relationships between support from father and mother, and life satisfaction. Bootstrapping was known as one of the most powerful and robust method in examining indirect effect (Preacher and Hayes, 2008).

As the model tested was a multi-mediator model, a macro developed by Preacher and Hayes (2008) was utilized to examining indirect effect of mediators. Indirect effect is found to be significant if zero is not within the $95 \%$ confidence interval. Based on bootstrapping analysis with 5000 resamples (Table 1), optimism has an indirect effect on relationship between support from mother and life satisfaction $\left(\beta_{\text {standardized }}=0.010, \mathrm{SE}=0.0039, \mathrm{CI}_{95}=0.0040,0.0199\right)$

Table 1 Results of bootstrapping, testing indirect effect of optimism and pessimism on the relationships between support form father and life satisfaction, as well as relationships between support from mother and life satisfaction.

\begin{tabular}{|c|c|c|c|c|}
\hline & \multicolumn{4}{|c|}{ Bootstrapping } \\
\hline & \multicolumn{2}{|c|}{$\mathrm{BC} 95 \% \mathrm{CI}$} & \multicolumn{2}{|c|}{$\mathrm{BC}_{\mathrm{a}} 95 \% \mathrm{CI}$} \\
\hline & Lower & Upper & Lower & Upper \\
\hline \multicolumn{5}{|c|}{$\begin{array}{l}\text { Support from Father } \rightarrow \\
\text { Life Satisfaction }\end{array}$} \\
\hline Optimism & -.0032 & .0089 & -.0033 & .0088 \\
\hline Pessimism & -.0035 & .0007 & -.0035 & .0007 \\
\hline \multicolumn{5}{|c|}{$\begin{array}{l}\text { Support from Mother } \rightarrow \\
\text { Life Satisfaction }\end{array}$} \\
\hline Optimism & .0040 & .0199 & .0040 & .0200 \\
\hline Pessimism & -.0051 & .0005 & -.0050 & .0006 \\
\hline
\end{tabular}




\section{Examining Invariance Across Gender}

In order to examine invariances across gender, multi group analysis was conducted. The model was found not stable across gender (Table 2). Unconstrained model is found to be superior compared to Fully Constrained model. The change of $\chi^{2}\left(\chi^{2}=172.75\right)$ is found to be significant at $p<.001$. This indicated presence of moderation effect of gender on the overall structural model.

Table 2 Results of multi group analysis across gender

\begin{tabular}{lcccc}
\hline & $\chi^{2}$ & $d f$ & $\chi^{2}$ change & $p$ value \\
\hline Fully Constrained & 727.82 & 328 & & .000 \\
\hline Unconstrained & 555.07 & 276 & 172.75 & \\
\hline
\end{tabular}

Furthermore, support from mother contributed to optimism $\left(\beta_{\text {standardized }}=0.014, p<.000\right)$ and optimism contributed to life satisfaction among adolescent boys $\left(\beta_{\text {standardized }}=0.24, p<.000\right)$, while effect was not found among adolescent girls.

\subsection{DISCUSSION AND CONCLUSION}

Results from this study reveals the importance of supports from parents on life satisfaction in adolescents. Supports from father and mother predicts level of life satisfaction in adolescents. Greater supports from father and mothers will predicts higher level of life satisfaction among adolescents. Adolescent developmental stage is known as a challenging stage, full with turbulence and stress. Adolescents who receive adequate supports from father and mother will feel loved and cared by parents, therefore be able to face turbulence and stress in their stressful developmental phase.

Besides, optimism and pessimism also predicts life satisfaction. Optimistic adolescents tend to be more satisfy with life and vice versa. This might due to the positive expectancy that optimistic adolescents are holding, which helps adolescents to have a better view towards their current life. Therefore, optimistic adolescents will be more satisfy with life compared with pessimistic adolescents.

However, support from father does not predicts optimism and pessimism. Malaysia is an Asia country in which Asian culture is deeply rooted within the country. In typical Asian culture father is usually the bread winner of the family that focuses on providing financial resources for the family. Father usually spend less time with family and children compared to mother. Therefore, it is not surprisingly that supports from father does not heavily influence development of adolescents' characteristics, such as optimism and pessimism.

In addition, optimism was found to mediate relationships between support from mother and life satisfaction. This indicated that with higher support from mother, the optimism level of adolescent will increases, which in turn heighten the level of life satisfaction. A plausible explanation for this phenomenon is that when adolescents receive sufficient support from mother, adolescents will develop a positive attitude towards self and future, which causes them to be happier and more satisfy with current life.

When examining in details for adolescent boys and adolescent girls groups, the influences of support from mother and optimism on life satisfaction is prominent in adolescent boys group. This suggests that adolescent boys might regard support from mother as a more crucial element in life compared to adolescent girls. Therefore, in order to help adolescent boys to cope with adolescent challenging phase, mothers need to form an even stronger bond and give necessary supports such as advices and helping behaviors regularly.

There are several limitations for this study. First of all, this study used self-administered questionnaire whereby data was obtained from adolescents only. A more comprehensive study can be carried out in future by collecting data from various sources, such as teacher, school, and friends. Furthermore, the cross-sectional design of this study might reduce the ability to explain and determine causality. Hence, result of this study must be interpreted with caution.

In conclusion, findings from this study was partially in line with the theoretical framework. As hypothesized earlier, greater support from mothers leads to greater life satisfaction in adolescents. Optimism has an indirect effects on the relationship between support from mothers and life satisfaction. Gender was found to moderate the structural relationships of supports from father and mother, optimism, and life satisfaction. Policy makers, school counsellors, and psychologist can include family and parents related variables, such as supports from parents, in promoting healthy development of adolescents.

\section{References}

Ash, C., \& Huebner, E.S. (2001). Environmental Events And Life Satisfaction Reports Of Adolescents: A Test Of Cognitive Mediation. School Psychology International, 22, 320-336.

Bandura, A. (1978), Social Learning Theory of Aggression. Journal of Communication, 28, 12-29. doi: 10.1111/j.1460-2466.1978.tb01621.x

Chong, W. H., Huan, V. S., Yeo, L. S., Ang, R. P. (2006). Asian Adolescents' Perceptions of Parent, Peer, and School Support and Psychological Adjustment: The Mediating Role of Dispositional Optimism. Current Psychology, 25(3), 212-228. doi: 10.1007/s12144-006-1004-6

Creed, P. A., Patton, W., and Bartum, D. (2002). Multidimensional Properties Of The Lot-R: Effects Of Optimism And Pessimism On Career And Well-Being Related Variables In Adolescents. Journal of Career Assessment, 10 (42). doi: 10.1177/1069072702010001003

Diener, E., Emmons, R. A., Larsen, R. J., \& Griffin, S. (1985). The Satisfaction with Life Scale.Journal of Personality Assessment, 49, 71-75.

Flouri, E., \& Buchanan, A. (2002). Life Satisfaction In Teenage Boys: The Moderating Role Of Father Involvement And Bullying. Aggressive Behavior, 28, 126-133.

Garcia, D. S. (2013). The Affective Temperaments and Well-Being: Swedish and Iranian Adolescents' Life Satisfaction and Psychological Well-Being. Journal Of Happiness Studies, 14(2), 689-707.

Gilman, R., \& Huebner, E.S. (2006). Characteristics of Adolescents Who Report Very High Life Satisfaction. Journal of Youth and Adolescence, 35, 311-319.

Huebner, E. S. (1995). The Students' Life Satisfaction Scale: An Assessment Of Psychometric Properties With Black And White Elementary School Students. Social Indicators Research, 34, $315-323$.

Malecki, C.K. \& Demaray, M.K. (2002). Measuring Perceived Social Support: Development of the Child and Adolescent Social Support Scale. Psychology in the Schools, 39, 1-18. 
Moksnes, U. A., Espnes, G.A. (2013). Self-Esteem And Life Satisfaction In Adolescents-Gender And Age As Potential Moderators. Quality Of Life Research, 22(10), 2921-2928.

Preacher, K. J., \& Hayes, A. F. (2008). Asymptotic and Resampling Strategies For Assessing And Comparing Indirect Effects In Multiple Mediator Models. Behavior Research Methods, 40, 879-891.

Salmela-Aro, K. H. \& Tuominen-Soini, H. (2010). Adolescents' Life Satisfaction During the Transition to Post-Comprehensive Education: Antecedents and Consequences. Journal Of Happiness Studies, 11(6), 683-701.

Scheier, M. F., Carver, C. S., and Bridges, M. W. (1994). Distinguishing Optimism From Neuroticism (And Trait Anxiety, Self-Mastery, And Self-Esteem): A Reevaluation Of The Life Orientation Test. Journal of Personality and Social Psychology, 67(6), 1063-1078. doi: 10.1037/0022-3514.67.6.1063

Suldo, S.M., \& Huebner, E.S. (2004a). Does Life Satisfaction Moderate The Effects Of Stressful Life Events On Psychopathological Behavior During Adolescence? School Psychology Quarterly, 19, 93-105.

Suldo, S.M., \& Huebner, E.S. (2004b). The Role Of Life Satisfaction In The Relationship Between Authoritative Parenting Dimensions And Adolescent Problem Behavior. Social Indicators Research, 66, 165-195.

Suldo, S. M., \& Huebner, E. S. (2006). Is Extremely High Life Satisfaction During Adolescence Advantageous? Social Indicators Research, 78, $179-203$.

Zimmerman, M.A., Salem, D.A., \& Maton, K.I. (1995). Family Structure And Psychosocial Correlates Among Urban African-American Adolescent Males. Child Development, 66, 1598-1613. 